\title{
Patients' Preferences Regarding Invasive Mediastinal Nodal Staging of Resectable Lung Cancer
}

\author{
Jelle E Bousema' \\ Fieke Hoeijmakers ${ }^{2}$ \\ Marcel GW Dijkgraaf ${ }^{3}$ \\ Jouke T Annema \\ Frank JC van den Broek' \\ $M$ Elske van den Akker- \\ van Marle ${ }^{5}$ \\ On behalf of the \\ MEDIASTrial Study Group
}

'Department of Surgery, Máxima MC, Veldhoven, 5500 MB, the Netherlands;

${ }^{2}$ Department of Surgery, Leiden

University Medical Center, Leiden, 2300

RC, the Netherlands; ${ }^{3}$ Department of

Epidemiology and Data Science,

Amsterdam UMC, University of

Amsterdam, Amsterdam, $1100 \mathrm{DE}$, the

Netherlands; ${ }^{4}$ Department of

Respiratory Medicine, Amsterdam UMC, University of Amsterdam, Amsterdam,

I 100 DE, the Netherlands; ${ }^{5}$ Department of Biomedical Data Sciences, Unit

Medical Decision Making, LUMC, Leiden, 2300 RC, the Netherlands
Correspondence: Frank JC van den Broek Department of Surgery, Máxima MC, Veldhoven, P.O. BOX 7777, Veldhoven, $5500 \mathrm{MB}$, the Netherlands

Email lung.resurge@mmc.nl
Background: Variability in practice and ongoing debate on optimal invasive mediastinal staging of patients with resectable non-small cell lung cancer (NSCLC) are widely described in the literature. Patients' preferences on this topic have, however, been underexposed so far. Methods: An internet-based questionnaire was distributed among MEDIASTrial participants (NTR6528, randomization of patients to mediastinoscopy or not in the case of negative endosonography). Literature, expert opinion and patient interviews resulted in five attributes: the risk of a futile lung resection (oncologically futile in case of unforeseen N2 disease), the length of the staging period, resection of the primary tumor, complications of staging procedures and the mediastinoscopy scar. The relative importance (RI) of each attribute was assessed by using adaptive conjoint analysis and hierarchical Bayes estimation. A treatment trade-off was used to examine the acceptable proportion of avoided futile lung resections to cover the burden of confirmatory mediastinoscopy.

Results: Ninety-seven patients completed the questionnaire (57\%). The length of the staging period was significantly the most important attribute (RI 26.24; 95\% CI: 25.05-27.43), followed by the risk of a futile surgical lung resection (RI 23.44; 95\% CI: 22.28-24.60) and resection of the primary tumor (RI 22.21; 95\% CI: 21.09-23.33). Avoidance of 7\% (IQR 1->14\%) futile lung resections would cover the burden of confirmatory mediastinoscopy, with a dichotomy among patients always $(39 \%)$ or never $(38 \%)$ willing to undergo confirmatory mediastinoscopy after N2 and N3-negative endosonography.

Conclusion: Although a strong dichotomy among patients always or never willing to undergo confirmatory mediastinoscopy was found, the length of the staging period was the most important attribute in invasive mediastinal staging according to patients with resectable NSCLC.

Trial Registration: Not applicable.

Keywords: patients' preferences, non-small cell lung cancer, mediastinal nodal staging, endosonography, mediastinoscopy, thoracic surgery

\section{Introduction}

Non-small cell lung cancer (NSCLC) is a common disease with 9623 new Dutch cases in $2020 .{ }^{1}$ Only $23 \%$ of patients are potential candidates for intended curative surgical treatment in the Netherlands, since the remaining $77 \%$ already have locoregional or distant metastases at the time of diagnosis. ${ }^{2}$ Potential surgical candidates with increased risk of locoregional metastases are recommended to undergo invasive mediastinal staging prior to surgical lung tumor resection. ${ }^{3}$ Adequate staging of these patients is important, as patients with N2 or N3 disease (stage III NSCLC) generally undergo definite chemoradiation or multimodality therapy that consists of neo-adjuvant chemoradiotherapy and subsequent surgical 
lung tumor resection. Upfront surgery in these patients seems to be associated with worse overall survival. ${ }^{4}$

The additional value of confirmatory mediastinoscopy after N2 and N3-negative endosonography results is under debate. In a randomized trial published in 2010 only $9 \%$ N2 or N3 metastases were detected after negative endosonography. ${ }^{5}$ This results in a number-needed-to-test of eleven, while mediastinoscopy is associated with significant risk of complications, hospital admission, general anesthesia and delay in definite lung cancer treatment. ${ }^{6-10}$ A recent meta-analysis including studies until 2019 revealed comparable unforeseen $\mathrm{N} 2$ rates after invasive mediastinal nodal staging by endosonography with or without mediastinoscopy, underlining the suggested limited additional diagnostic value of confirmatory mediastinoscopy. ${ }^{10}$

Despite extensive research on the value and accuracy of endosonography and cervical mediastinoscopy in NSCLC staging, patients' preferences have, in this era of shared decision making, never been investigated before. Therefore, we aimed to determine patients' preferences on invasive mediastinal staging addressing the burden of care, burden of complications and prognostic uncertainties of staging strategies with or without confirmatory mediastinoscopy.

\section{Patients and Methods}

\section{Research Questions}

1. What are the most important attributes of invasive mediastinal nodal staging according to patients with resectable NSCLC?

2. What do NSCLC patients consider a minimum proportion of avoided futile surgical lung tumor resections (defined as demonstrating unforeseen N2 after surgery) to accept the burden of confirmatory mediastinoscopy after N2 and N3-negative endosonography?

\section{Design}

An internet-based questionnaire consisting of adaptive conjoint analysis (ACA) and treatment trade-off method (TTM) was developed using Sawtooth Software Lighthouse Studio version 9.8.0. Background information about mediastinal nodal staging by using endosonography (conscious sedation, 1\% complications) and cervical mediastinoscopy (general anesthesia, scar, 3\% complications, laryngeal recurrent nerve palsy) as well as surgical lung tumor resection with mediastinal lymph node dissection (18\% minor complications, $2 \%$ major complications, $2 \%$ mortality) was provided in the introduction of the questionnaire. After the introduction the ACA was used to determine the most important attributes of invasive mediastinal staging. The considered minimum proportion of avoided futile surgical lung tumor resections to accept the burden of confirmatory mediastinoscopy after N2 and N3-negative endosonography was determined by the TTM.

\section{Study Population}

All patients participating in the randomized MEDIASTrial (NTR6528) were potentially eligible for participation in this study. Depending on randomization, patients underwent surgical lung tumor resection and lobe-specific mediastinal lymph node dissection with or without prior cervical mediastinoscopy after negative endosonography. ${ }^{11}$ At least three months after lung surgery all patients received a written invitation to participate in this patients' preferences study. In case the questionnaire was not completed within three weeks a written reminder was sent. Patients who already withdrew consent for the MEDIASTrial were not invited.

\section{Collection of Attributes}

We used literature to collect possible attributes associated with invasive mediastinal staging. The most reported outcomes were listed and sent to 20 local investigators of the MEDIASTrial (10 pulmonologists and 10 lung surgeons) in order to get an "expert opinion" of the most important attributes. The experts selected all attributes they thought to be important on the list and were able to add important attributes, which resulted in a list of 13 attributes as displayed in Table 1. These attributes were integrated in semi-structured interviews with five patients from the Dutch lung cancer patients' association (Longkanker NL). The interviews consisted of three parts: background information, open questions to identify additional attributes and ranking of the attributes listed by the experts. Taking the feasibility of the final questionnaire into account, we aimed to select five attributes. Therefore, all patients were asked to rank the attributes, resulting in the following five most important attributes from the interviews: the risk of a futile surgical lung tumor resection (with its inherent morbidity and mortality), the risk of complications of staging procedures, the length of the staging period, a scar in the neck from the mediastinoscopy and actual resection of the primary lung tumor. 
Table I Attributes Based on Literature and Expert Opinion

Clinical relevance of mediastinal staging (eg, treatment choice)

Cost-effectiveness of mediastinal staging

Effect of unforeseen N2 disease on survival

Maximum accuracy of mediastinal staging

Negative predictive value of endosonography

Negative predictive value of mediastinoscopy

Patients' comfort during staging procedures

Risk of complications of futile surgical lung tumor resection

Risk of complications of staging procedures

Sensitivity of endosonography

Sensitivity of mediastinoscopy

The total length of the staging period

The total number of staging procedures

These five attributes were included in the ACA to determine their relative importance. The lay-out and formulations of the created questionnaire were pilot-tested by another five patients from the Dutch lung cancer patients' association before it was distributed among included patients.

\section{Adaptive Conjoint Analysis}

After determining the ACA attributes, we adjusted realistic levels to them based on literature and clinical practice (Table 2). Before the start of the ACA, an explanation of the attributes was provided (Table 2), including an ACA example task. The first part of the ACA consisted of questions to indicate the relevance of the difference between the highest and lowest level within each attribute on a four-point scale: not important at all - a little bit important - important - very important. Based on the results of the attribute relevance questions, individualized trade-offs between two scenarios were constructed. The minimum number of trade-offs needed for accurate estimations of probability utilities was 12 , based on the following formula: $3 \times(\mathrm{N}-\mathrm{n}-1)-\mathrm{N}$, where $\mathrm{N}$ is the total number of levels and $\mathrm{n}$ is the number of attributes. ${ }^{12}$ Patients were exposed to six considerations of scenarios with two attributes, and six considerations of scenarios with three attributes. Patients indicated which scenario they preferred and the strength of their preference (sevenpoint scale) by making trade-offs between preferred and adverse outcomes. Probabilities were described in frequency formats to facilitate understanding (example ACA task in Figure 1). ${ }^{13}$ To prevent clinically irrelevant or impossible considerations, some restrictions were made (eg, scar in the neck if mediastinoscopy was omitted).

\section{Treatment Trade-off Method}

In the ASTER trial unforeseen N2 rates of $6.9 \%$ after endosonography and mediastinoscopy versus $14.3 \%$ after mediastinoscopy only were found. ${ }^{5}$ Despite this difference in unforeseen $\mathrm{N} 2$ disease, the five-year survival was $35 \%$ in both groups. ${ }^{14}$ Based on these results we suggested that up to $14 \%$ futile surgical lung tumor resections would not compromise long-term survival. The TTM contained several choice sets between two scenarios: a scenario with mediastinoscopy (scenario A) and without mediastinoscopy (scenario B) and its effect on the proportion of avoided futile surgical lung tumors resections. It was stated that survival was similar in both scenarios.

We started with a choice set in which scenario A included 100 patients in whom confirmatory mediastinoscopy was performed, resulting in 14 avoided futile surgical lung tumor resections at the cost of six patients with complications of mediastinoscopy (three patients with mild complications and three patients with severe life-threatening complications). Scenario B was a fixed scenario including 100 patients not undergoing mediastinoscopy and thus no patients suffering from complications of mediastinoscopy, resulting in zero avoided futile surgical lung tumor resections (corresponding with an unforeseen N2: 14\%). When patients chose scenario A (with mediastinoscopy) the number of avoided futile surgical lung tumor resections in scenario A decreased in order to determine whether a decreased value of mediastinoscopy would still cover the burden of mediastinoscopy. When patients chose scenario B (without mediastinoscopy) in this first choice set, they were asked again with additional explanation. If they maintained their preference for scenario $\mathrm{B}$, the TTM ended for them; these patients were classified as "would never undergo mediastinoscopy". In subsequent choice sets (for patients choosing scenario A in the first choice set) the number of avoided futile surgical lung tumor resections in scenario A (with mediastinoscopy) decreased or increased when patients respectively chose scenario A or B in order to determine whether the decreased or increased value of mediastinoscopy would cover the burden (example TTM task in Figure 2). In this way an acceptable proportion of avoided futile surgical lung tumor resections to cover the burden of confirmatory mediastinoscopy was established for all patients.

\section{Data Analysis}

Randomization allocation, age and gender of included patients were retrieved from the MEDIASTrial database. Hierarchical Bayes estimation was used to calculate the 
Table 2 Adaptive Conjoint Analysis Attributes with Their Levels and Explanation to the Patients

\begin{tabular}{|c|c|c|}
\hline Attribute & Explanation to Patients & Levels \\
\hline $\begin{array}{l}\text { Futile surgical lung } \\
\text { tumor resection }\end{array}$ & $\begin{array}{l}\text { Surgical lung tumor resection was futile in case unforeseen N2 disease is detected after } \\
\text { surgery. Your survival will not be extended as result of the surgery, while surgical lung tumor } \\
\text { resection is associated with } 30 \% \text { overall complications ( } 18 \% \text { mild complications, } 10 \% \text { severe } \\
\text { complications, } 2 \% \text { mortality). The levels represent the proportion of futile surgical lung } \\
\text { tumor resections. }\end{array}$ & $\begin{array}{l}3 \% \\
6 \% \\
9 \% \\
12 \%\end{array}$ \\
\hline $\begin{array}{l}\text { Complications of } \\
\text { staging procedures }\end{array}$ & $\begin{array}{l}\text { During the invasive mediastinal nodal staging procedures complications could occur. } \\
\text { However, complications are rare, some could be severe. }\end{array}$ & $\begin{array}{l}0 \% \\
4 \% \\
6 \% \\
8 \%\end{array}$ \\
\hline $\begin{array}{l}\text { Length of staging } \\
\text { period }\end{array}$ & $\begin{array}{l}\text { The process of scheduling, performing and pathology investigation of confirmatory } \\
\text { mediastinoscopy takes time. This process has to be completed before lung cancer treatment } \\
\text { can start, and therefore this will be prolonged by performing confirmatory mediastinoscopy. } \\
\text { On the other hand, confirmatory mediastinoscopy can prevent you from futile lung surgery. }\end{array}$ & $\begin{array}{l}\text { I week } \\
3 \text { weeks } \\
5 \text { weeks }\end{array}$ \\
\hline $\begin{array}{l}\text { Resection of the lung } \\
\text { tumor }\end{array}$ & $\begin{array}{l}\text { When confirmatory mediastinoscopy is omitted you will directly be referred for surgical lung } \\
\text { tumor resection. When confirmatory mediastinoscopy is not omitted, the surgical lung } \\
\text { tumor resection will only be performed if mediastinoscopy does not show mediastinal lymph } \\
\text { node metastases. If mediastinal lymph node metastases are detected at mediastinoscopy, } \\
\text { generally no surgical lung tumor resection will be performed. }\end{array}$ & $\begin{array}{l}\text { Always } \\
\text { Only if mediastinoscopy } \\
\text { is N2-3-negative }\end{array}$ \\
\hline $\begin{array}{l}\text { Mediastinoscopy scar } \\
\text { in the neck }\end{array}$ & $\begin{array}{l}\text { Cervical mediastinoscopy is performed through an incision in the neck. A scar of } \\
\text { approximately } 3-4 \text { centimeter just above the sternum will be created. }\end{array}$ & $\begin{array}{l}\text { Yes } \\
\text { No }\end{array}$ \\
\hline
\end{tabular}

relative importance $(\mathrm{RI})$ of all attributes from the ACA, by using the maximum difference in the average overall utility levels within an attribute. ${ }^{15}$ The RI of an attribute represents its weight compared to the other attributes, since the sum of the RIs is always 100. The mean RIs of the attributes were compared to each other by using the paired $T$-test. Subgroup analysis to assess whether different groups assigned different RIs to specific attributes was carried out using the independent $T$-test based on the accepted proportion of avoided futile lung tumor resections obtained from the TTM (below/equal or above the median), MEDIASTrial randomization allocation (ie, mediastinal staging with or without confirmatory mediastinoscopy), age at time of diagnosis (below/equal or above the median) and on gender. All analyses were performed by using Sawtooth Software Lighthouse Studio 9.8.0 (Sawtooth Software, Inc., Sequim, WA, USA) and the Statistical Package for Social Sciences, version 22.0 (SPSS Inc., Chicago, IL, USA).

\section{Results}

\section{Patients}

A total of 97 patients completed the questionnaire and were included for analysis (response rate: 57\%). The median age of included patients was 67 years (IQR 61$72)$, and $55 \%(53 / 97)$ were males. As a result of randomization in the MEDIASTrial, 52 patients underwent endosonography only and 45 patients underwent endosonography and confirmatory mediastinoscopy prior to surgical lung tumor resection. Responders were younger than non-responders (67 years [IQR 61-72] vs 71 years [IQR 64-75], $p=0.012$ ). No differences were found among responders and non-responders in randomization outcome and gender.

\section{Relative Importance of Attributes}

The most important attribute of invasive mediastinal nodal staging of NSCLC was the length of the staging period (RI 26.24; 95\% CI: 25.05-27.43), followed by the risk of a futile surgical lung tumor resection (RI 23.44; 95\% CI: 22.28-24.60), actual resection of the primary lung tumor (RI 22.21; 95\% CI: 21.09-23.33), complications of staging procedures (RI 20.65; 95\% CI: 20.09-21.20) and the mediastinoscopy scar (RI 7.46; 95\% CI: 6.87-8.05) (Table 3). The length of the staging period was more important than all other attributes (futile lung tumor resection $p=0.009$, other attributes $p=0.000)$. The risk of a futile surgical lung tumor resection and actual resection of the primary lung 
Scenario A

surgical lung tumour resections of 100 patients

12 futile

complications of staging procedures of 100 patients

\section{0 with}

Length of staging period 5 weeks
Scenario $B$

surgical lung tumour resections of 100 patients

3 futile 97 useful

\section{8 useful}

100 without

\section{complications of staging procedures of 100 patients}

6 with

Length of staging period 3 weeks

94 without

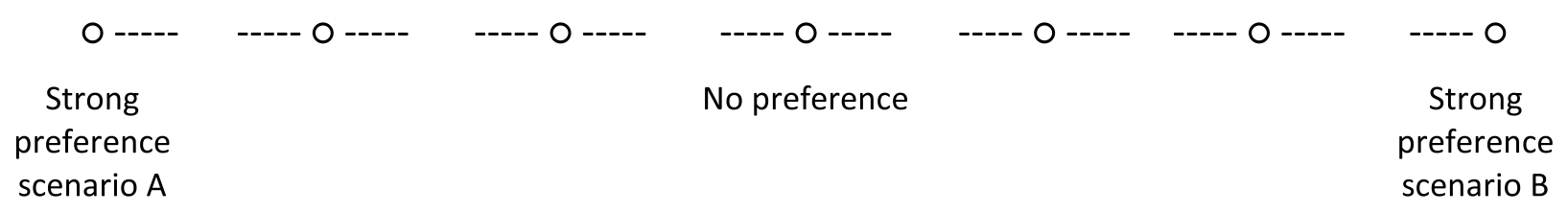

Figure I Example adaptive conjoint analysis trade-off containing three attributes.

Which scenario for invasive mediastinal staging do you prefer?

With mediastinoscopy:

100 patients mediastinoscopy

6 patients complications of mediastinoscopy

7 futile surgical lung tumour resections avoided

\section{Without mediastinoscopy:}

0 patients mediastinoscopy

0 patients complications of mediastinoscopy

0 futile surgical lung tumour resections avoided

\section{Complication of surgical lung tumour resection: 30 out of 100 patients.}

Figure 2 Example treatment trade-off.

tumor were evenly important ( $p=0.199)$, while both were more important than complications of staging procedures ( $p=0.000$ and $p=0.044$, respectively). The scar from the mediastinoscopy was the least important attribute ( $p=0.000$ compared to all other attributes).

\section{Mediastinoscopy Treatment Trade-off Method}

The minimum acceptable proportion of avoided futile surgical lung resections to accept the burden of confirmatory mediastinoscopy was 7\% (IQR 1->14\%). A dichotomy in patients' preferences was, however, found; 39\% (38/97) of patients would always undergo mediastinoscopy, even if it avoids only $1 \%$ futile surgical lung tumor resections. On the other hand, $38 \%$ (37/97) of patients would never undergo mediastinoscopy, even if it avoids 14\% futile surgical lung tumor resections (Figure 3). The TTM preferences (tending towards omitting or performing confirmatory mediastinoscopy) were in concordance with the randomization allocation in $73 \%$ of patients who underwent mediastinoscopy and $67 \%$ in whom mediastinoscopy was omitted $(p=0.522)$.

\section{Subgroup Analysis}

Comparison of the ACA results of MEDIASTrial randomization allocation subgroups showed that patients in whom 
Table 3 Adaptive Conjoint Analysis Results $(n=97)$

\begin{tabular}{|l|c|c|}
\hline $\begin{array}{l}\text { Attributes and } \\
\text { Levels }\end{array}$ & $\begin{array}{c}\text { Average } \\
\text { Utility (SD) }\end{array}$ & $\begin{array}{c}\text { Average Relative } \\
\text { Importance (95\% CI) }\end{array}$ \\
\hline $\begin{array}{l}\text { Length of the staging } \\
\text { period } \\
\text { I week }\end{array}$ & $26.24(25.05-27.43)$ \\
3 weeks & $63.74(13.7 I)$ & \\
5 weeks & $3.72(5.84)$ & \\
\hline $\begin{array}{l}\text { Futile surgical lung } \\
\text { tumor resection } \\
3 \%\end{array}$ & $-67.46(16.35)$ & \\
$6 \%$ & $58.32(13.25)$ & \\
$9 \%$ & $23.85(8.68)$ & \\
I2\% & $-23.28(6.89)$ & \\
\hline Resection of the lung & $-58.88(15.68)$ & \\
tumor & & $22.28-24.60)$ \\
Always & & \\
If mediastinoscopy & $-55.53(13.84)$ & \\
N2-3-negative & & \\
\hline Complications of & & \\
staging procedures & & \\
$0 \%$ & $50.78(5.84)$ & \\
$4 \%$ & $18.14(4.04)$ & \\
$6 \%$ & $-16.46(2.48)$ & \\
$8 \%$ & $-52.46(8.07)$ & \\
\hline $\begin{array}{l}\text { Mediastinoscopy scar } \\
\text { in the neck }\end{array}$ & \\
Yes & & \\
No & & \\
\hline
\end{tabular}

Abbreviations: SD, standard deviation; $\mathrm{Cl}$, confidence interval.

confirmatory mediastinoscopy was omitted assigned the length of the staging period as single most important attribute, with actual resection of the primary tumor as second attribute. Patients who underwent confirmatory mediastinoscopy ranked the risk of a futile lung tumor resection, length of the staging period and actual resection of the primary tumor respectively as most important attributes, without significant differences among them (Table 4).

When comparing patients based on age at time of diagnosis ( $\leq 67$ years vs $>67$ years), we found that the length of the staging period was ranked as the most important attribute in both groups. Older patients, however, found the risk of a futile surgical lung tumor resection as important as the length of the staging period. In the other attributes no differences among age subgroups were found (Table 4). Subgroup analysis based on gender showed no differences in RIs of all attributes.
When comparing patients based on the outcome of the TTM, we found that patients tending towards the use of confirmatory mediastinoscopy (TTM $\leq 7$ avoided futile surgical lung resections) ranked the risk of a futile lung tumor resection, length of the staging period and actual resection of the primary tumor as most important attributes, without significant differences among them. Patients tending towards omitting confirmatory mediastinoscopy (TTM $>7$ avoided futile surgical lung resections) ranked the length of the staging period as single most important attribute (Table 4).

\section{Discussion}

The present study indicated that NSCLC patients with an indication for invasive mediastinal staging determined the length of the staging period the most important attribute of invasive staging, while futile surgical lung resections (eg, unforeseen $\mathrm{N} 2$ after resection) and actual resection of the primary lung tumor were the second most important attributes. On average, avoidance of $7 \%$ futile surgical lung tumor resections would cover the burden of confirmatory mediastinoscopy. However, a dichotomy among patients always or never willing to undergo confirmatory mediastinoscopy was found.

The European guidelines on invasive mediastinal nodal staging in selected patients are clear about the preference of endosonography over surgical staging as initial staging technique. However, in case of negative endosonography results (no pathologically proven $\mathrm{N} 2$ or $\mathrm{N} 3$ metastases) confirmatory mediastinoscopy is recommended in patients with $\mathrm{cN} 1-3$ and should be considered in patients with centrally located, FDG-non-avid or peripheral tumors $>3 \mathrm{~cm}$. This leaves room for doctor's preferences and/or shared decision making, resulting in an ongoing debate in scientific forums in literature and variation in daily practice. $^{6-10}$ Significant variability in the use of invasive staging was already described in the United States, Canada and the Netherlands. ${ }^{16-18}$ Shared decision making is currently upcoming and would, in our opinion, perfectly fit in the abovementioned knowledge gap, awaiting further research on this topic. Our results suggest that lung cancer patients have explicit ideas about invasive mediastinal staging, and the period diagnosing and staging lung cancer is generally very emotional and precarious. Patient preferences on invasive mediastinal lung cancer staging have, however, never been investigated before. Several interview-based studies on treatment preferences showed that 


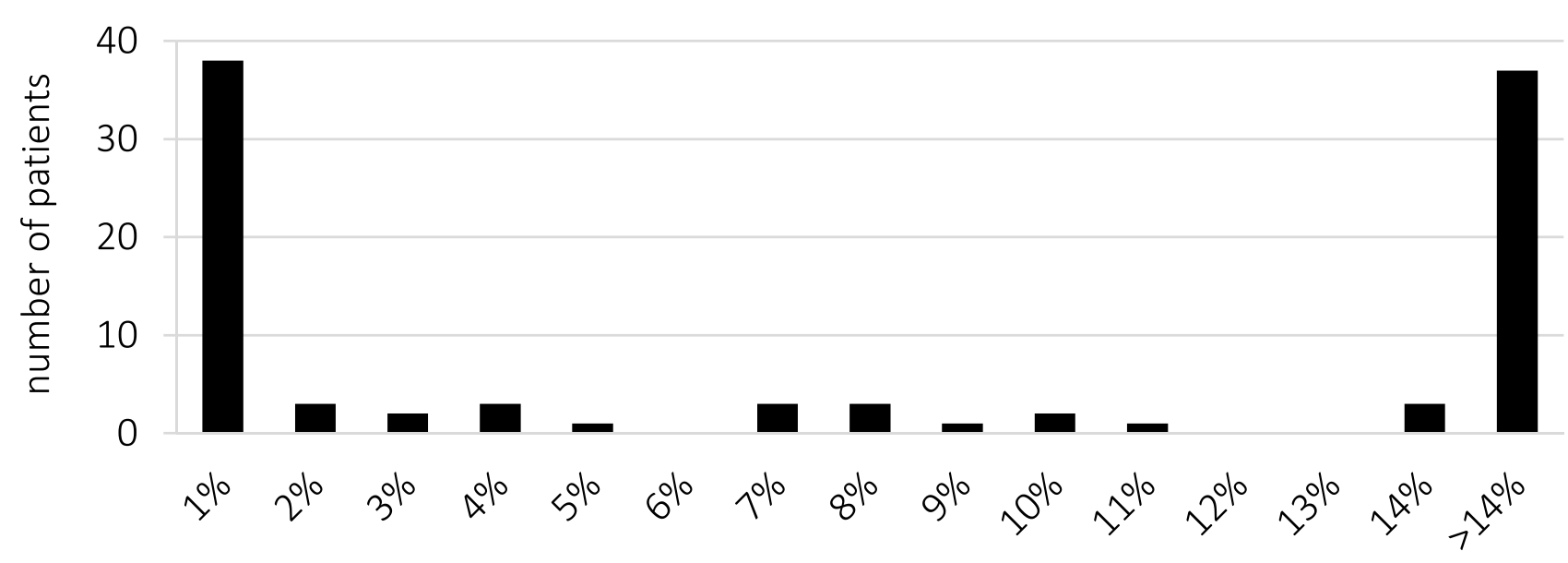

proportion avoided futile surgical lung tumour resections

Figure 3 Minimum proportion of avoided futile surgical lung tumor resections to accept the burden of confirmatory mediastinoscopy after N2 and N3-negative endosonography based on TTM ( $n=97)$.

lung cancer patients had clear ideas about efficacy and burden of lung cancer treatment. ${ }^{19-23}$ These findings were strengthened by the results of a study including stage I-II NSCLC patients showing that most of these patients found it important to be involved in treatment decision making. ${ }^{24}$ In this era of shared decision making, physicians should therefore consider to invite patients to participate in their staging process.

A key element of shared decision making is providing patients with sufficient information. ${ }^{25} \mathrm{Up}$ to one-fifth of patients in the abovementioned stage I-II NSCLC study reported lack of knowledge about the treatment options. ${ }^{24}$ Added to the assumption that cancer patients in general are at risk of overestimating their life expectancy and expectations about medical treatment, an important role is reserved for the information-providing doctor. ${ }^{26}$

When considering to omit confirmatory mediastinoscopy after negative endosonography, it is important to inform patients about the potential oncological consequences. Patients with extensive mediastinal lymph node metastases (stage III NSCLC), detected at mediastinal staging, are generally treated by definitive chemoradiotherapy or a multimodality strategy of induction therapy followed by surgery. The randomized PACIFIC trial showed that application of durvalumab after chemoradiotherapy in patients with locally advanced NSCLC (stage III) improved overall survival. ${ }^{27}$ However, in patients with limited N2 disease (single station or only microscopic metastases) long-term survival of patients treated by induction therapy followed by surgical lung tumor resection was better compared to patients who underwent primary surgical lung tumor resection and adjuvant therapy in several studies. ${ }^{4,28-30}$ In contrast, patients with minimal $\mathrm{N} 2$ disease (metastases $<2 \mathrm{~mm}$ and/or metastases in 1 lymph node station only) are thought not to have compromised survival by primary surgical treatment followed by adjuvant chemoradiotherapy.

Most unforeseen N2 metastases turned out to be minimal N2 in previous studies, thus prompting the question whether resection of unforeseen $\mathrm{N} 2$ should be defined as "futile" after all. Since best treatment of N2 disease is an ongoing debate among physicians, inclusion of this minimal N2 issue in the informed consent conversation with patients may make it even more complicated for patients. Therefore we chose a more conservative approach in the present study to investigate the patients' opinion about "futile" resection.

Against our expectations, the risk of complications by mediastinoscopy was not considered as important as the attributes "period of staging", "futile lung resection" and "actual resection of the primary tumor". Moreover, the accuracy of mediastinoscopy (as overall accuracy, sensitivity or negative predictive value) was not considered by our patient panel at all to include this as an attribute in the adaptive conjoint analysis, although the risk of a futile lung resection may be an equivalent (according to patients) of diagnostic accuracy. Evaluation of mediastinoscopy in the Netherlands from 2012 to 2016 demonstrated that only half of the mediastinoscopies were performed according to the Dutch guideline (requiring biopsies of two ipsilateral 
Table 4 Relative Importance and Rank of Attributes Subgroup Analyses

\begin{tabular}{|c|c|c|c|c|c|}
\hline & \multicolumn{2}{|c|}{$\begin{array}{l}\text { TTM Using Confirmatory Mediastinoscopy } \\
\qquad(n=50)\end{array}$} & \multicolumn{2}{|c|}{$\begin{array}{l}\text { TTM Omitting Confirmatory Mediastinoscopy } \\
\qquad(n=47)\end{array}$} & \multirow{2}{*}{$\begin{array}{c}p \text { value } \\
0.033\end{array}$} \\
\hline Length of the staging period & 2 & $25.0 \mathrm{I}(23.30-26.7 \mathrm{I})$ & 1 & $27.56(25.91-29.20)$ & \\
\hline Futile surgical lung tumor resection & I & 25.19 (23.59-26.77) & 3 & $21.59(20.00-23.17)$ & 0.002 \\
\hline Resection of the lung tumor & 3 & $22.50(20.8 \mathrm{I}-24.20)$ & 2 & $21.89(20.40-23.40)$ & 0.593 \\
\hline Complications of staging procedures & 4 & $20.59(19.80-21.38)$ & 4 & $20.7 \mid(|9.9|-21.5 I)$ & 0.833 \\
\hline \multirow[t]{2}{*}{ Mediastinoscopy scar } & 5 & 6.71 (6.09-7.34) & 5 & $8.25(7.25-9.24)$ & 0.009 \\
\hline & \multicolumn{2}{|c|}{ Randomization: with Mediastinoscopy $(n=45)$} & \multicolumn{2}{|c|}{$\begin{array}{l}\text { Randomization: Without Mediastinoscopy } \\
\qquad(n=52)\end{array}$} & $p$ value \\
\hline Length of the staging period & 2 & $24.17(22.33-26.01)$ & 1 & $28.03(26.60-29.46)$ & 0.001 \\
\hline Futile surgical lung tumor resection & I & $25.93(24.18-27.69)$ & 3 & $21.28(19.96-22.61)$ & 0.000 \\
\hline Resection of the lung tumor & 3 & 22.19 (20.39-23.99) & 2 & $22.23(20.79-23.67)$ & 0.974 \\
\hline Complications of staging procedures & 4 & $20.96(20.14-21.78)$ & 4 & $20.38(19.62-21.14)$ & 0.301 \\
\hline \multirow[t]{2}{*}{ Mediastinoscopy scar } & 5 & $6.75(5.95-7.4 I)$ & 5 & $8.08(7.23-8.91)$ & 0.025 \\
\hline & \multicolumn{2}{|c|}{ Age Below/Equal Median ( $\leq 67$ Years) $(n=49)$} & \multicolumn{2}{|c|}{ Age Above Median (>67 Years) $(n=48)$} & $p$ value \\
\hline Length of the staging period & I & $26.96(25.38-28.55)$ & 1 & $25.50(23.68-27.33)$ & 0.227 \\
\hline Futile surgical lung tumor resection & 3 & $22.21(20.69-23.73)$ & 2 & $24.69(22.96-26.44)$ & 0.032 \\
\hline Resection of the lung tumor & 2 & $22.94(21.46-24.42)$ & 3 & $21.47(19.76-23.17)$ & 0.192 \\
\hline Complications of staging procedures & 4 & $20.10(19.31-20.89)$ & 4 & $21.21(20.44-21.97)$ & 0.047 \\
\hline Mediastinoscopy scar & 5 & $7.79(6.73-8.85)$ & 5 & $7.12(6.59-7.65)$ & 0.265 \\
\hline
\end{tabular}

stations, one contralateral station and N7). This may have resulted in significantly more unforeseen $\mathrm{N} 2$ disease in the non-adherence group compared to patients who underwent complete mediastinoscopy. ${ }^{31}$ A meta-analysis including studies until September 2019 showed comparable unforeseen $\mathrm{N} 2$ rates after invasive mediastinal nodal staging by endosonography with or without mediastinoscopy. ${ }^{10}$ When evaluating complications as well as accuracy in our treatment trade-off method, we found a clear dichotomy in our study results, with approximately $40 \%$ always choosing mediastinoscopy and $40 \%$ always choosing to omit mediastinoscopy. Whether the occurrence of complications or a futile resection has contributed to their choices remains unclear, but we cannot ignore the fact that $70 \%$ of patients answered the TTM conform their randomization allocation suggesting that cognitive dissonance reduction could have influenced patients' choices. This psychologic phenomenon is based on the assumption that patients who have experienced a certain treatment or disease assign higher utilities to that treatment or disease. ${ }^{32}$

One of the shortcomings of the present study may be that the included patients have been a selected sample, as they were patients who already underwent invasive staging (endosonography with or without mediastinoscopy according to randomization) and surgical lung tumor resection. In advance, we suggested that a certain knowledge and experience with lung cancer staging and treatment was required to properly judge which attributes were most important. For patients without this experience it would have been very hard to acknowledge the effects of the disease and its staging and surgical treatment. Moreover, the time between lung cancer diagnosis, invasive staging and surgery is, as result of the guideline recommendations, very short in the Netherlands. Since this period is generally very precarious for patients, we thought it would not be ethical to present this questionnaire to them in this period.

As cognitive dissonance reduction could have influenced patients' choices, it may therefore be valuable to assess patients in whom mediastinal nodal staging is not yet performed. Special attention to detailed background information and patients' well-being should hereby be taken into account.

Also, the strong dichotomy in the TTM results might be (partly) a result of insufficient understanding of the considerations to be made or the method used to do so (TTM), despite a confirmatory question that was added to the questionnaire. Therefore, in future research it could be considered to use an interview setting instead of an internet-based questionnaire. Availability of this study as an 
internet-based questionnaire only could also have induced the age difference among responders and non-responders. However, in subgroup analysis based on age, the length of the staging period remained the most important attribute. The increased RI of the risk of a futile lung resection in older patients could be explained by older patients probably being more prudent of futile major surgery based on an inferior general condition compared to younger patients. The actual length of the staging period of included patients was not available, and subanalysis for this attribute was therefore not possible.

This is the first study on patients' preferences on invasive nodal staging of NSCLC. The results of this study show that patients have preferences on this topic, taking into account the burden of care, burden of complications and prognostic uncertainties of different staging strategies and dependent treatments.

\section{Conclusions}

Although a strong dichotomy among patients always or never willing to undergo confirmatory mediastinoscopy was found, the length of the staging period was the most important attribute in invasive mediastinal staging according to patients with resectable NSCLC. While we await further research on the optimal strategy for invasive mediastinal nodal staging, local staging logistics could already be optimized, and shared decision making could be considered to fulfil patient preferences.

\section{Abbreviations}

NSCLC, non-small cell lung cancer; RI, relative importance; EBUS, endobronchial ultrasonography; EUS, endoscopic ultrasonography; ACA, adaptive conjoint analysis; TTM, treatment trade-off method; IQR, interquartile range; $\mathrm{CI}$, confidence interval.

\section{List of Definitions}

EBUS(-TBNA) endobronchial ultrasound guided transbronchial needle aspiration: Investigation of mediastinal and hilar lymph nodes with a linear ultrasound probe via the airways with the possibility of nodal sampling under real-time ultrasound control.

EUS(-FNA) endoscopic ultrasound guided fine needle aspiration: Investigation of mediastinal lymph nodes with a linear ultrasound probe via the esophagus with the possibility of nodal sampling under real-time ultrasound control.
Futile surgical lung tumor resection: A surgical lung tumor resection was deemed oncologically futile in case unforeseen N2 (macro-metastases or multi-level) disease was detected after surgery, as overall survival of these patients is generally not extended as a result of the surgery.

Mediastinal staging: Invasive mediastinal nodal staging to determine the nodal status of lung cancer by using EBUS, EUS and/or mediastinoscopy.

Mediastinoscopy: Surgical procedure under general anesthesia to examine mediastinal lymph nodes, located paratracheal and subcarinal, with the possibility to take surgical biopsies.

Negative endosonography: Endosonographic examination of mediastinal lymph nodes by using EBUS-TBNA and/or EUS-FNA showing no pathologically proven N2 or N3 lymph node metastases.

Unforeseen N2: Pathologically proven N2 disease resulting from mediastinal lymph node dissection at time of tumor resection, not detected by clinical staging including endosonography or mediastinoscopy (if performed).

\section{Data Sharing Statement}

The datasets used and/or analyzed during the current study are available from the corresponding author on reasonable request.

\section{Ethics Approval and Consent to Participate}

This study was performed in accordance with the declaration of Helsinki, 64th WMA General Assembly, Fortaleza, Brazil, October 2013 and in accordance with the Medical Research Involving Human Subjects Act (WMO, the Netherlands). The medical ethical committee of Máxima MC approved the study protocol, and written informed consent was obtained from all patients.

\section{Acknowledgments}

Beside the authors of this article the following steering group members and local investigators are members of the MEDIASTrial study group:

Nicole E Papen-Botterhuis

Department of Research and Innovation, Máxima MC, Veldhoven, the Netherlands

Maggy Youssef-El Soud

Department of Pulmonary Medicine, Máxima MC, Veldhoven, the Netherlands

Wim J van Boven 
Department of Cardiothoracic Surgery, Amsterdam UMC, University of Amsterdam, Amsterdam, the Netherlands

Johannes MA Daniels

Department of Pulmonary Medicine, Amsterdam UMC, VU University Medical Center, Amsterdam, the Netherlands

David J Heineman

Department of Surgery, Amsterdam UMC, VU University Medical Center, Amsterdam, the Netherlands

Department of Cardiothoracic Surgery, Amsterdam UMC, VU University Medical Center, Amsterdam, the Netherlands

Harmen R Zandbergen

Department of Cardiothoracic Surgery, Amsterdam UMC, VU University Medical Center, Amsterdam, the Netherlands

Pepijn Brocken

Department of Pulmonary Medicine, HagaZiekenhuis,

Den Haag, the Netherlands

Thirza Horn

Department of Surgery, HagaZiekenhuis, Den Haag, the Netherlands

Willem H Steup

Department of Surgery, HagaZiekenhuis, Den Haag, the Netherlands

Jerry Braun

Department of Cardiothoracic Surgery, Leiden University Medical Center, Leiden, the Netherlands

Rajen SRS Ramai

Department of Pulmonary Medicine, Leiden University

Medical Center, Leiden, the Netherlands

Naomi Beck

Dutch Institute for Clinical Auditing, Leiden, the Netherlands

Nicole P Barlo

Department of Pulmonary Medicine, Noordwest Ziekenhuisgroep, Alkmaar, the Netherlands

Martijn van Dorp

Department of Surgery, Noordwest Ziekenhuisgroep, Alkmaar, the Netherlands

W Hermien Schreurs

Department of Surgery, Noordwest Ziekenhuisgroep, Alkmaar, the Netherlands

Anne-Marie C Dingemans

Department of Pulmonary Medicine, Maastricht University Medical Center, Maastricht, the Netherlands Jos G Maessen
Department of Cardiothoracic Surgery, Maastricht University Medical Center, Maastricht, the Netherlands Erik HFM van der Heijden

Department of Pulmonary Medicine, Radboud University Medical Center, Nijmegen, the Netherlands

\section{Ad FTM Verhagen}

Department of Cardiothoracic Surgery, Radboud University Medical Center, Nijmegen, the Netherlands

Niels JM Claessens

Department of Pulmonary Medicine, Rijnstate ziekenhuis, Arnhem, the Netherlands

Jan-Willem HP Lardenoije

Department of Surgery, Rijnstate ziekenhuis, Arnhem, the Netherlands

Birgitta I Hiddinga

Department of Pulmonary Medicine, University of Groningen, University Medical Center Groningen, Groningen, the Netherlands

Caroline van de Wauwer

Department of Cardiothoracic Surgery, University of Groningen, University Medical Center Groningen, Groningen, the Netherlands

Anthonie J van der Wekken

Department of Pulmonary Medicine, University of Groningen, University Medical Center Groningen, Groningen, the Netherlands

Wessel E Hanselaar

Department of Pulmonary Medicine, Franciscus Gasthuis en Vlietland, Rotterdam, the Netherlands

Robert TJ Kortekaas

Department of Surgery, Franciscus Gasthuis en Vlietland, Rotterdam, the Netherlands

Martin P Bard

Department of Pulmonary Medicine, Spaarne Gasthuis, Hoofddorp, the Netherlands

Herman Rijna

Department of Surgery, Spaarne Gasthuis, Hoofddorp, the Netherlands

\section{Gerben P Bootsma}

Department of Pulmonary Medicine, Zuyderland Medical Center, Heerlen, the Netherlands

Yvonne LJ Vissers

Department of Surgery, Zuyderland Medical Center, Heerlen, the Netherlands

Eelco J Veen

Department of Surgery, Amphia, Breda, the Netherlands

Cor $\mathrm{H}$ van der Leest 
Department of Pulmonary Medicine, Amphia, Breda, the Netherlands

Emanuel Citgez

Department of Pulmonary Medicine, Medisch Spectrum Twente, Enschede, the Netherlands

Eino B van Duyn

Department of Surgery, Medisch Spectrum Twente, Enschede, the Netherlands

Geertruid MH Marres

Department of Surgery, Albert Schweitzer Ziekenhuis, Dordrecht, the Netherlands

Eric R van Thiel

Department of Pulmonary Medicine, Albert Schweitzer

Ziekenhuis, Dordrecht, the Netherlands

Paul E van Schil

Department of Thoracic and Vascular Surgery,

Antwerp University Hospital, Antwerp, Belgium

Jan P van Meerbeeck

Department of Pulmonary Medicine, Antwerp

University Hospital, Antwerp, Belgium

Niels Smakman

Department of Surgery, Diakonessenhuis, Utrecht, the

Netherlands

Femke van der Meer

Department of Pulmonary Medicine, Diakonessenhuis,

Utrecht, the Netherlands

Mohammed D Saboerali

Department of Pulmonary Medicine,

Beatrixziekenhuis, Gorinchem, the Netherlands

Anne Marie Bosch

Department of Surgery, Ziekenhuis Gelderse Vallei,

Ede, the Netherlands

Wouter $\mathrm{K}$ de Jong

Department of Pulmonary Medicine, Ziekenhuis

Gelderse Vallei, Ede, the Netherlands

Charles C van Rossem

Department of Surgery, Maasstad Ziekenhuis,

Rotterdam, the Netherlands

W Johan Lie

Department of Pulmonary Medicine, Maasstad Ziekenhuis, Rotterdam, the Netherlands

Ewout A Kouwenhoven

Department of Surgery, ZiekenhuisGroep Twente, Almelo, the Netherlands

A Jeske Staal-van den Brekel

Department of Pulmonary Medicine, ZiekenhuisGroep

Twente, Almelo, the Netherlands

Nike M Hanneman
Department of Surgery, Ikazia Ziekenhuis, Rotterdam, the Netherlands

Roxane Heller-Baan

Department of Pulmonary Medicine, Ikazia Ziekenhuis, Rotterdam, the Netherlands

Valentin JJM Noyez

Department of Vascular and Thoracic Surgery, SintMaarten General Hospital, Mechelen, the Netherlands

\section{Author Contributions}

All authors made substantial contributions to conception and design, acquisition of data, or analysis and interpretation of data; took part in drafting the article or revising it critically for important intellectual content; agreed to submit to the current journal; gave final approval of the version to be published; and agree to be accountable for all aspects of the work.

\section{Funding}

This patients' preferences study is part of the MEDIASTrial which is funded by ZonMw (project number 843004109) and The Dutch Cancer Society (project number 11313). The funding sources had no involvement in the study design, data analysis and interpretation and the decision to submit the article for publication.

\section{Disclosure}

Dr Bousema and Dr van den Broek report research grants from ZonMw and the Dutch Cancer Society, during the conduct of this study. Prof. Dr Annema reports nonfinancial support from Hitachi Medical systems and Pentax and a grant from Cook Medical, outside the submitted work. The authors report no other conflicts of interest in this work.

\section{References}

1. Integraal Kanker Centrum Nederland, (IKNL). Cijfers over kanker (Dutch cancer registry); 2019. Available from: http://www.cijfersover kanker.nl/selecties/Dataset_2/img5a4b6b6782289. Accessed October 30, 2019.

2. Heineman DJ, Hoeijmakers F, Beck N, et al. Impact of health care organization on surgical lung cancer care. Lung Cancer. 2019;135:181-187. doi:10.1016/j.lungcan.2019.07.028

3. Vilmann P, Clementsen PF, Colella S, et al. Combined endobronchial and esophageal endosonography for the diagnosis and staging of lung cancer: European Society of Gastrointestinal Endoscopy (ESGE) guideline, in cooperation with the European Respiratory Society (ERS) and the European Society of Thoracic Surgeons (ESTS). Endoscopy. 2015;47(6):546-560.

4. Postmus PE, Kerr KM, Oudkerk M, et al. Early and locally advanced non-small-cell lung cancer (NSCLC): ESMO clinical practice guidelines for diagnosis, treatment and follow-up. Ann Oncol. 2017;28(4): iv1-iv21. doi:10.1093/annonc/mdx222 
5. Annema JT, van Meerbeeck JP, Rintoul RC, et al. Mediastinoscopy vs endosonography for mediastinal nodal staging of lung cancer: a randomized trial. JAMA. 2010;304(20):2245-2252. doi:10.1001/ jama.2010.1705

6. Rusch VW. Mediastinoscopy: an obsolete procedure? J Thorac Cardiovasc Surg. 2011;142(6):1400-1402. doi:10.1016/j. jtcvs.2011.10.017

7. Annema JT, de Leyn P, Clementsen P, Siemsen M, Vilmann P. Mediastinoscopy after negative endoscopic mediastinal nodal staging: can it be omitted? Eur Respir J. 2015;46(6):1848-1849. doi:10.1183/13993003.01472-2015

8. Kim H. Reply to "are we at the dusk of mediastinoscopy in modern clinical practice?": an irresistible trend. J Thorac Oncol. 2015;10(9): e91-e92. doi:10.1097/JTO.0000000000000595

9. Verhagen AFTM, Schuurbiers OCJ, Looijen-Salamon MG, et al. Mediastinal staging in daily practice: endosonography, followed by cervical mediastinoscopy. Do we really need both? Interact Cardiovasc Thorac Surg. 2013;17(5):823-828.

10. Bousema JE, van Dorp M, Noyez VJJM, Dijkgraaf MGW, Annema JT, van den Broek FJC. Unforeseen N2 disease after negative endosonography findings with or without confirmatory mediastinoscopy in resectable non-small cell lung cancer: a systematic review and meta-analysis. J Thorac Oncol. 2019;14(6):979-992. doi:10.1016/j.jtho.2019.02.032

11. Bousema JE, Dijkgraaf MGW, Papen-Botterhuis NE, et al. MEDIASTinal staging of non-small cell lung cancer by endobronchial and endoscopic ultrasonography with or without additional surgical mediastinoscopy (MEDIASTrial): study protocol of a multicenter randomised controlled trial. BMC Surg. 2018;18 (1):27. doi:10.1186/s12893-018-0359-6

12. Sawtooth Software. ACA technical paper V6.0; 2007.

13. Gigerenzer G. The psychology of good judgment: frequency formats and simple algorithms. Med Decis Making. 1996;16(3):273. doi:10.1177/0272989X9601600312

14. Kuijvenhoven JC, Korevaar DA, Tournoy KG, et al. Five-year survival after endosonography vs mediastinoscopy for mediastinal nodal staging of lung cancer. JAMA. 2016;316(10):1110-1112. doi:10.1001/ jama.2016.10349

15. Orme B. Hierarchical Bayes: Why All the Attention? Sawtooth Software Inc.; 2000.

16. Turner SR, Seyednejad N, Nasir BS. Patterns of practice in mediastinal lymph node staging for non-small cell lung cancer in Canada. Ann Thorac Surg. 2018;106(2):428-434. doi:10.1016/j. athoracsur.2018.02.054

17. Thornblade LW, Wood DE, Mulligan MS, et al. Variability in invasive mediastinal staging for lung cancer: a multicenter regional study. J Thorac Cardiovasc Surg. 2018;155(6):2658-2671.e1. doi:10.1016/ j.jtcvs.2017.12.138

18. Bousema JE, van Dorp M, Hoeijmakers F, et al. Guideline adherence of mediastinal staging of non-small cell lung cancer: a multicentre retrospective analysis. Lung Cancer. 2019;134:52-58. doi:10.1016/j. lungcan.2019.05.031
19. Schmidt K, Damm K, Prenzler A, Golpon H, Welte T. Preferences of lung cancer patients for treatment and decision-making: a systematic literature review. Eur J Cancer Care (Engl). 2016;25(4):580-591. doi:10.1111/ecc.12425

20. Sun $\mathrm{H}$, Wang $\mathrm{H}, \mathrm{Xu} \mathrm{N}$, et al. Patient preferences for chemotherapy in the treatment of non-small cell lung cancer: a multicenter Discrete Choice Experiment (DCE) Study in China. Patient Prefer Adherence. 2019;13:1701-1709. doi:10.2147/PPA.S224529

21. Mühlbacher AC, Bethge S. Patients' preferences: a discrete-choice experiment for treatment of non-small-cell lung cancer. Eur J Health Econ. 2015;16(6):657-670. doi:10.1007/s10198-014-0622-4

22. Sullivan DR, Eden KB, Dieckmann NF, et al. Understanding patients' values and preferences regarding early stage lung cancer treatment decision making. Lung Cancer. 2019;131:47-57. doi:10.1016/j. lungcan.2019.03.009

23. Janssen EM, Dy SM, Meara AS, Kneuertz PJ, Presley CJ, Bridges JF. Analysis of patient preferences in lung cancer - estimating acceptable tradeoffs between treatment benefit and side effects. Patient Prefer Adherence. 2020;14:927-937. doi:10.2147/PPA.S235430

24. Mokhles S, Nuyttens JJME, de Mol M, et al. Treatment selection of early stage non-small cell lung cancer: the role of the patient in clinical decision making. BMC Cancer. 2018;18(1):79. doi:10.1186/ s12885-018-3986-5

25. Abbett SK, Urman RD, Bader AM. Shared decision-making - creating pathways and models of care. Best practice \& research. Clin Anaesthesiol. 2020;34(2):297-301.

26. Weeks JC, Catalano PJ, Cronin A, et al. Patients' expectations about effects of chemotherapy for advanced cancer. $N$ Engl J Med. 2012;367(17):1616-1625. doi:10.1056/NEJMoa1204410

27. Antonia SJ, Villegas A, Daniel D, et al. Durvalumab after chemoradiotherapy in stage III non-small-cell lung cancer. $N$ Engl J Med. 2017;377(20):1919-1929. doi:10.1056/NEJMoa1709937

28. Dickhoff C, Dahele M, de Langen AJ, et al. Population-based patterns of surgical care for stage IIIA NSCLC in the Netherlands between 2010 and 2013. J Thorac Oncol. 2016;11(4):566-572. doi:10.1016/j.jtho.2016.01.002

29. Thomas D, Thomas D, Arnold B, et al. The significance of upfront knowledge of N2 disease in non-small cell lung cancer. World J Surg. 2018;42(1):161-171. doi:10.1007/s00268-017-4165-6

30. Eberhardt WEE, De Ruysscher D, Weder W, et al. 2nd ESMO consensus conference in lung cancer: locally advanced stage III non-small-cell lung cancer. Ann Oncol. 2015;26(8):1573-1588. doi:10.1093/annonc/mdv187

31. Hoeijmakers F, Heineman DJ, Beck N, et al. Mediastinoscopy for staging of non-small cell lung cancer: surgical performance in the Netherlands. Ann Thorac Surg. 2019;107(4):1024-1031.

32. Stiggelbout AM, de Haes JCJM. Patient preference for cancer therapy: an overview of measurement approaches. J Clin Oncol. 2001;19 (1):220-230. doi:10.1200/JCO.2001.19.1.220
Patient Preference and Adherence

\section{Publish your work in this journal}

Patient Preference and Adherence is an international, peer-reviewed, open access journal that focusing on the growing importance of patient preference and adherence throughout the therapeutic continuum. Patient satisfaction, acceptability, quality of life, compliance, persistence and their role in developing new therapeutic modalities and compounds to optimize clinical outcomes for existing disease states are major areas of interest for the journal. This journal has been accepted for indexing on PubMed Central. The manuscript management system is completely online and includes a very quick and fair peer-review system, which is all easy to use. Visit http:// www.dovepress.com/testimonials.php to read real quotes from published authors. 